\title{
Mechanical and chemical analyses across dental porcelain fused to CP titanium or Ti6Al4V
}

\author{
Júlio C.M. Souza ${ }^{\mathrm{a}, \mathrm{d}, *}$, Bruno Henriques ${ }^{\mathrm{a}, \mathrm{b}, *}$, Edith Ariza $^{\mathrm{a}}$, Antonio E. Martinelli ${ }^{\mathrm{b}}$, Rubens M. Nascimento ${ }^{\mathrm{b}}$, \\ Filipe S. Silva ${ }^{a}$, Luís A. Rocha ${ }^{\mathrm{a}, \mathrm{e}}$, Jean-Pierre Celis ${ }^{\mathrm{c}}$
}

a Centre of Microelectromechanical Systems (CMEMS), Dept. of Mechanical Engineering, Universidade do Minho, P-4800-058 Guimarães, Portugal

b Dept. Materials Engineering, Universidade Federal do Rio Grande do Norte (UFRN), 59072-970 Natal, RN, Brazil

c Dept. MTM, Katholieke Universiteit Leuven, B-3001 Leuven, Belgium

d PPGO, CCS, Dept. of Dentistry (ODT), Universidade Federal de Santa Catarina (UFSC), 88040-900 Florianópolis, SC, Brazil

e Dept. of Physics, Universidade Estadual Paulista “Júlio de Mesquita Filho” (UNESP), 17033-360, Bauru SP, Brazil

\section{A R T I C L E I N F O}

\section{Article history:}

Received 8 September 2013

Received in revised form 22 November 2013

Accepted 17 December 2013

Available online 3 January 2014

\section{Keywords:}

Titanium

Dental porcelain

Metal-ceramic interface

Mechanical properties

Nanoindentation

Chemical analysis

\begin{abstract}
A B S T R A C T
The aim of this study was to evaluate the evolution of mechanical properties and chemical variation across veneering dental porcelain fused to different titanium-based substrates. Test samples were synthesized by fusing dental feldspar-based porcelain onto commercially pure titanium grade II or Ti6Al4V alloy. Samples were cross-sectioned at angles of 10 and $90^{\circ}$ to the interface plane. Afterwards, nanoindentation tests and Scanning Electron Microscopy (SEM) imaging coupled to an Energy Dispersive Spectroscopy (EDS) system were carried out across interfaces extending from the metal towards the porcelain area. Elemental diffusion profiles across the porcelain-to-metal interfaces were also obtained by EDS analysis. The mismatch in mechanical properties found in porcelain-to-Ti6Al4V interfaces was lower than that of porcelain-to-CP titanium. Cracking was noticed at low-thickness veneering dental porcelain regions after the nanoindentation tests of samples cross-sectioned at low angles to the interface plane. A wide reaction zone between titanium and porcelain as well as higher incidence of defects was noticed at the porcelain-to-CP titanium interfaces. This study confirmed Ti6Al4V as an improved alternative to $\mathrm{CP}$-titanium as it showed to establish a better interface with the veneering dental porcelain considering the slight chemical interaction and the lower mechanical properties mismatch. The elastic modulus of porcelain-to-Ti6Al4V samples showed to be less sensitive to porcelain thickness variations.
\end{abstract}

(c) 2013 Elsevier B.V. All rights reserved.

\section{Contents}

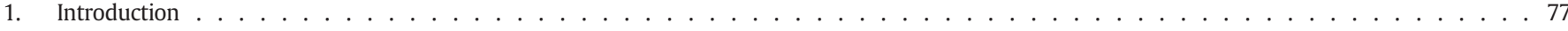

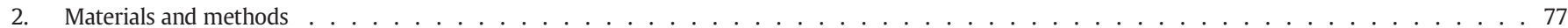

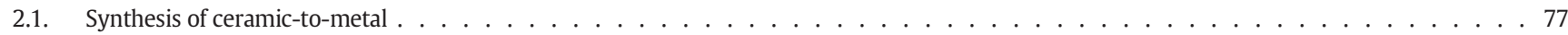

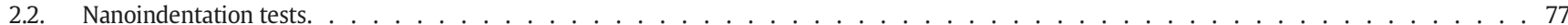

2.3. Chemical and microstructural analyses . . . . . . . . . . . . . . . . . . . . . . . . . . .

3. Results . . . 78

3.1. Chemical characterization of the base materials . . . . . . . . . . . . . . . . . . . . . . . . . . . . . . . . . . 78

3.2. Chemical and microscopic analyses of the interfaces . . . . . . . . . . . . . . . . . . . . . . . . . . . 78

3.3. Mechanical behavior across porcelain-to-titanium interfaces by nanoindentation . . . . . . . . . . . . . . . . . . . . . . . . . 78

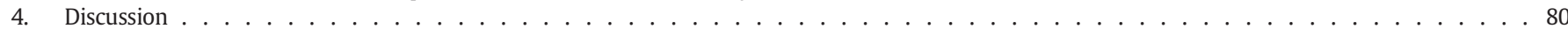

4.1. Chemical analysis of metal-ceramic interfaces. . . . . . . . . . . . . . . . . . . . . . . . . . . . . 80

4.2. Mechanical analysis of metal-ceramic interfaces. . . . . . . . . . . . . . . . . . . . . . . . . . . . 81

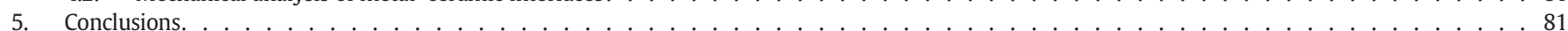

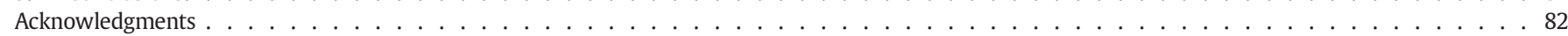

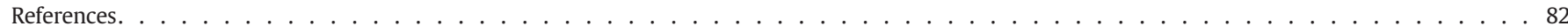

* Corresponding author at: Centre of Microelectromechanical Systems (CMEMS), Dept. of Mechanical Engineering, Universidade do Minho, Campus de Azurém, 4800-058 Guimarães, Portugal. Tel.: + 351 253510220; fax: + 351253516007.

E-mail address: jsouza@dem.uminho.pt (J.C.M. Souza). 


\section{Introduction}

Metal-ceramic prostheses are one of the most important examples of dental restorations used to replace teeth crowns supported by dental tissues or implants [1-4]. Such prostheses are made of veneering feldspar-based porcelains fused onto metallic substrates. The metallic structure provides the required strength while the ceramic veneer provides the esthetics [1-4]. Layers of dental porcelain are applied onto the metallic substrates to obtain multilayered systems that mimic the optical properties of tooth structures $[5,6]$. In this process, both materials and equipment have to be considered $[2,5,7,8]$. Thus, the risk of failures depends on the skills of prosthetic technicians and on the technique sensitivity [2,5-8]. Failure cases in metal-ceramic restorations have been reported ranging from $3 \%$ up to $14 \%$ after an observation period of 5 years [9-11]. Those failures are mainly attributed to different causes such as interfacial defects [2,12], ceramic fracture mostly arising from the weak adhesion between metal and porcelain [9], mismatch in the coefficient of linear thermal expansion between materials [13], and caries due to the accumulation of biofilms surrounding metal-ceramic prostheses [10].

Titanium has been commonly used in orthopedic and dental implants due to its biocompatibility and high corrosion resistance $[1,14,15]$. However, the use of titanium in metal-ceramic restorations has shown some technical complications [8,16-20]. One of the complaints is that titanium is highly reactive during the thermal treatment of the porcelain layers above $800{ }^{\circ} \mathrm{C}$ forming a thick oxide surface layer at low-vacuum atmosphere $[8,16,17,19,20]$. Such layer can decrease the bond strength between titanium alloys and porcelain $[8,16,17,19,20]$. Consequently, the thermal treatment of veneering dental porcelain coupled to titanium must be carried out in argon or in a high-vacuum atmosphere to avoid an excessive oxidation of titanium thus improving the titanium-porcelain bond strength $[8,16]$.

Nowadays, scientific developments on veneering dental porcelains to titanium have been made to improve the mechanical strength of the porcelain-to-titanium interface $[2,18,22-24]$. The effect of different bonders on the adhesion of two dental porcelains (GC initial-Ti and Duceram plus) to machined CP titanium grade II (Wiron99) has been tested by four-point bending tests [22]. Metal-ceramic interfaces with a gold bonder (GC bonder) exhibited the highest rate of strain energy release of porcelain-to-titanium interfaces. Another study reported an increase of the titanium-to-porcelain bond strength by $21 \%$ and $25 \%$ by applying a coating of $\mathrm{SiO}_{2}$ and $\mathrm{SiO}_{2}-$ $\mathrm{TiO}_{2}$ onto CP titanium, respectively [24]. On the other hand, the bond strength of titanium alloy-to-porcelain interfaces increased by $14 \%$ and $28 \%$ when coated with $\mathrm{SiO}_{2}$ and $\mathrm{SiO}_{2}-\mathrm{TiO}_{2}$, respectively. Coatings of $\mathrm{SiO}_{2}, \mathrm{SiO}_{2}-\mathrm{TiO}_{2}$, TiN or $\mathrm{ZrSiN}$ act as barriers of multilayered titanium materials during the thermal treatment of feldsparbased porcelains [23-25]. In fact, the use of novel bonding agents associated with titanium alloys can smoothen abrupt changes in chemical and mechanical properties across porcelain-to-metal interfaces, resulting in a mechanical improvement of metal-to-porcelain interfaces $[21,26]$. A recent study reports enhanced shear bond strength by $160 \%$ on using an interlayer composite based on 40 $60 \%$ gold powder and $40-60 \%$ porcelain [26]. Bending or shear strength tests are commonly used to determine the mechanical behavior of veneering dental porcelain to titanium [2,6,21-27]. However, nano-scale mechanical tests are alternative methods especially suited to characterize the mechanical properties of multilayered systems [28]. These tests consist of nanoindentation measurements performed on polished cross-sections made at different angles relative to the direction of the interfaces. This technique was performed in this study to characterize the mechanical behavior of veneering porcelain fused to commercially pure titanium or Ti6Al4V substrates. Chemical and microscopic characteristics of the porcelain layer fused to Ti-based substrates were also reported.

\section{Materials and methods}

\subsection{Synthesis of ceramic-to-metal}

Twenty cylindrical substrates $(10 \times 10 \mathrm{~mm})$ composed of $\mathrm{CP}$ titanium grade II (VSMPO TIRUS, US, ASTM B 348, Grade 2) or Ti6Al4V (VSMPO TIRUS, US, ASTM B 348, Grade V) were wet ground down to 1200 mesh by using $\mathrm{SiC}$ sandpapers and then polished with colloidal silica solution (OPS, Struers A/S; Denmark) with particles at diameter $0.04 \mu \mathrm{m}$. After that, those metallic cylinders were ultrasonically cleaned in isopropyl alcohol for $10 \mathrm{~min}$, and then in distilled water for $5 \mathrm{~min}$. Afterwards, the substrates were stored in a desiccator before applying the opaque veneering feldspar-based porcelain (Noritake Ti 22; Japan).

The opaque dental porcelain powder was mixed with distilled water in a ratio of $2: 1$ (by mass) to obtain a creamy porcelain slurry. Subsequently, the porcelain slurry was applied onto metallic substrates under ultrasonic vibration. The porcelain slurry was heated up to $800{ }^{\circ} \mathrm{C}$ at a heating rate of $10^{\circ} \mathrm{C} \mathrm{min}^{-1}$ in a high-vacuum furnace at $2 \mathrm{mbar}\left(\mathrm{pO}_{2}=0.15 \mathrm{~cm} \mathrm{Hg}\right)$. At $800{ }^{\circ} \mathrm{C}$, the power of the heating furnace was shut down and the porcelain-to-metal assemblies were cooled down under vacuum atmosphere at 2 mbar. The coefficient of linear thermal expansion (CTE) value of the veneering porcelain $\left(8.9 \times 10^{-6}{ }^{\circ} \mathrm{C}\right)$ was close to that showed for $\mathrm{CP}$ titanium $\left(9.1 \times 10^{-6}{ }^{\circ} \mathrm{C}\right)$ and Ti6AlV $\left(9.2 \times 10^{-6}{ }^{\circ} \mathrm{C}\right)$. The match of CTE between those materials decreases the concentration of residual stresses across the interfaces considering previous studies $[2,26,27,31,36]$.

After firing cycle, the porcelain-to-metal assemblies were embedded in a glass fiber composite and sectioned at angles of 10 and $90^{\circ}$ relative to the interface plane. The cross-sectioning was carried out by wet grinding on SiC paper from 380 down to 1200 mesh followed by polishing with colloidal silica (OPS, diameter of $0.04 \mu \mathrm{m})$.

\subsection{Nanoindentation tests}

Indentation tests were carried out with the loading axis at angles of $90^{\circ}$ and $10^{\circ}$ relative to the porcelain-to-titanium interfaces (Fig. 1). A nano-hardness tester (Nano Instruments, Inc. Knoxville; TN, USA) operated with a Berkovich diamond pyramid tip (apex angle of $143^{\circ}$ ) was used to make nanoscopic indentations in triplicate along the cross-sectioned test samples $(n=15)$. Loads of 20 and $80 \mathrm{mN}$ were applied onto the metallic substrates and on the veneering porcelain, respectively, during $15 \mathrm{~s}$. Mechanical properties of the veneering porcelain fused onto titanium substrates were obtained as a function of the position of the indenter axis relative to the porcelain-to-titanium interface. The shape function was determined by the Oliver \& Pharr method (1992). Nanoindentation tests performed at $90^{\circ}$ relative to the interfaces allow evaluating stress/strain

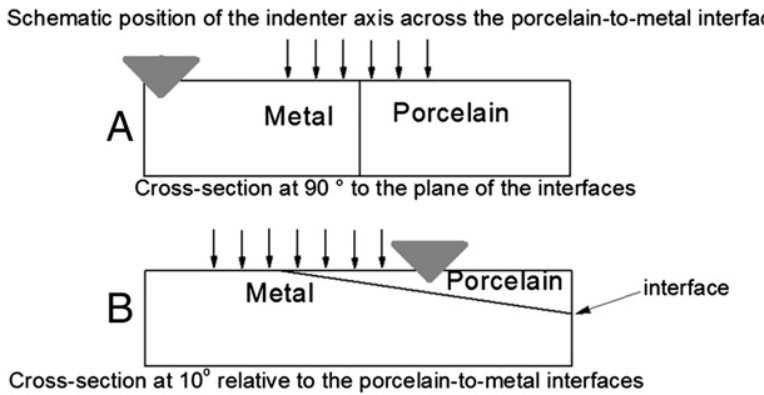

Fig. 1. Nanoindentation tests on (A) a perpendicular cross-section and (B) on a low angle $\left(10^{\circ}\right)$ cross-section to the plane of the metal-ceramic interfaces. Berkovich pyramid tip (apex angle of $143^{\circ}$, shape function determined by Oliver \& Phar method). 


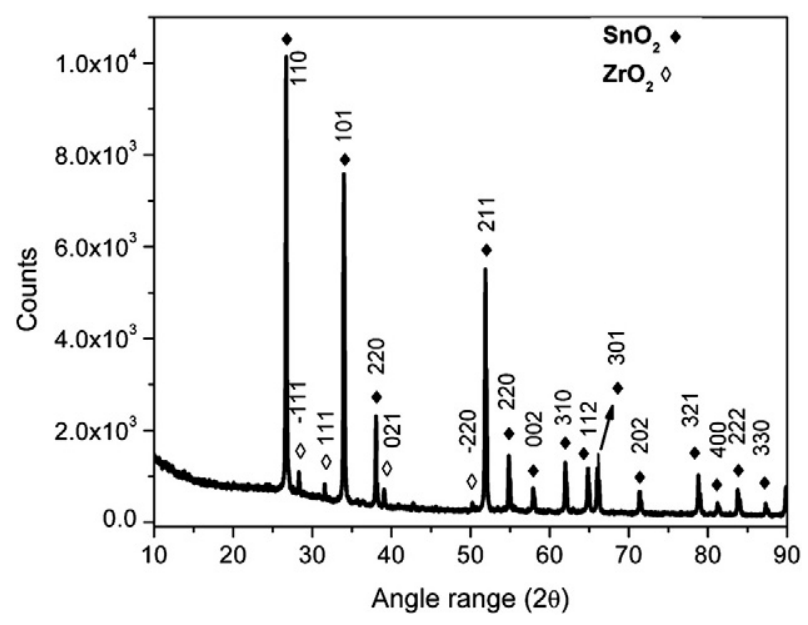

Fig. 2. X-ray diffraction patterns of opaque dental porcelain. $\mathrm{Cu}-\mathrm{K} \alpha$ radiation (1.54056 ̊)), scanning rate of $1.5^{\circ} \mathrm{min}^{-1}$, voltage of $40 \mathrm{kV}$ and current of $30 \mathrm{~mA}$.

fields induced during indentation across interfaces with respect to the displacement axis of the indenter. On the other hand, the variation of the mechanical properties relative to the porcelain thickness can be evaluated by nanoindentation tests performed across metal-ceramic interfaces sectioned at $10^{\circ}$.

\subsection{Chemical and microstructural analyses}

Before fusing porcelain to metal, the porcelain powders used in this work were analyzed in a Shimadzu 6000 diffractometer with $\mathrm{Cu}-\mathrm{K} \alpha$ radiation $\left(1.54056 \AA\right.$ ) ranging from 5 to $75^{\circ}(2 \theta)$. The scanning rate was $1.5^{\circ} \mathrm{min}^{-1}$, the voltage was $40 \mathrm{kV}$, and the current was $30 \mathrm{~mA}$. The porcelain powder was also analyzed by X-ray fluorescence. The chemical composition of the titanium substrate was provided by the manufacturer.

Veneering porcelains fused to titanium-based substrates were inspected by Scanning Electron Microscopy (LEICA CAMBRIDGE SEMS360) and Field-Emission Scanning Electron Microscopy (FESEM, FEI Quanta, 400 FEG) before and after nanoindentation tests. The elemental distribution across the metal-ceramic interfaces was carried out by Energy Dispersive X-ray spectroscopy (EDAX), to obtain the chemical composition profile along the metal-ceramic transition that comprised the metal side, the interfacial region and the porcelain layer ( 8 points in the metal substrate and 8 points in the porcelain layer).

\section{Results}

\subsection{Chemical characterization of the base materials}

The X-ray diffraction spectrum of the opaque dental porcelain commercially recommended for the synthesis of veneering porcelain-totitanium assemblies is shown in Fig. 2. It reveals the presence of $\mathrm{SnO}_{2}$, and $\mathrm{ZrO}_{2}$ as the main crystalline phases. The chemical analysis of the opaque bonding porcelain was obtained by X-ray fluorescence and is given in Table 1.

\subsection{Chemical and microscopic analyses of the interfaces}

The micrographs of the interface region of dental porcelain to $\mathrm{CP}$ titanium or Ti6Al4V as well as the elemental distribution across the interface are shown in Fig. 3. The elemental profiles show similar behavior in both types of metal-ceramic couples except for the case of aluminum $(\mathrm{Al})$ profile, which displayed a distinct behavior in the case of CP Ti and Ti6Al4V. The Al profile of the veneering porcelain-toTi6Al4V sample showed an upward trend from the bulk until the interface region, where is suddenly ceased and followed by a sharp decrease in content before the porcelain layer. The concentration of aluminum in the porcelain layer remained steady in the range of $4 \mathrm{wt} . \%$. The same concentration of Al was found in the porcelain layer of the porcelainto-CP titanium specimen, but less than $2 \mathrm{wt}$ \% was found in the metal side, which must have diffused from the veneering porcelain as $\mathrm{CP}$ titanium did not contain aluminum in its former composition. As mentioned above, the other elements displayed similar diffusion behavior. Hence, neither titanium (Ti) could be noticed in the porcelain layer or silicon ( $\mathrm{Si}$ ) could be noticed in the metal substrate of both types of metal-ceramic couples. The oxygen $(0)$ profile was reproduced in both specimens, and showed a steep drop within the porcelain layer from $90 \mathrm{wt} . \%$ to $60 \mathrm{wt} . \%$. At the metal-ceramic interface, another abrupt drop could be noticed, from $60 \mathrm{wt} . \%$ of the porcelain side to $10 \mathrm{wt} . \%$ of the metal substrate, remaining roughly bellow this value along the metallic substrate. The elemental analyses also revealed diffusion of sodium (Na), up to $2 \mathrm{wt} . \%$, and traces of potassium (K) and tin $(\mathrm{Sn})$ in the metal substrate, either CP titanium or Ti6Al4V.

The high magnification SEM micrographs of veneering porcelainto-CP titanium and veneering porcelain-to-Ti6Al4V are shown in Figs. 4 and 5, respectively. Micrographs indicate that signs of a strong chemical reaction (white arrows) between the Ti-based substrate and dental veneering porcelain are visible in $\mathrm{Z2}$ (Figs. 4A and 5A). Defects (dark arrows) are also noticed at the substrate near the ceramic-to-metal interface that may lead to the weakening of the bond and consequently to the failure of the system. The number of defects was higher at the porcelain-to-CP titanium interface region than at the porcelain-to-Ti6Al4V one, most probably due to the high reactivity of CP titanium.

\subsection{Mechanical behavior across porcelain-to-titanium interfaces by nanoindentation}

The hardness and elastic modulus, as function of the lateral position of the nano-indenter across the metal-ceramic interface, are shown in Figs. 6 and 7 for nano-indentations performed at $90^{\circ}$ and $10^{\circ}$ relative to the metal-ceramic interface. The bulk properties of $\mathrm{CP}$ titanium, Ti6Al4V and dental porcelain obtained by nanoindentation at $90^{\circ}$ relative to the metal-ceramic interface are shown in Table 2.

On veneering porcelain-to-CP titanium samples, measurements at $90^{\circ}$ showed a slight increase of the elastic modulus of titanium from $142 \mathrm{GPa}$, measured away from the interface region, to $157 \mathrm{GPa}$, measured near the interface. An important thing to point out is the elastic modulus of $160 \mathrm{GPa}$ measured at the veneering porcelain close to the interface. This atypical value for porcelain elastic modulus may be related to the strong and wide reaction occurred between CP titanium and porcelain, which have imparted a modification of the elastic modulus of the porcelain at this site. A same increasing trend was observed for

Table 1

Chemical composition of opaque dental porcelain obtained by X-ray fluorescence. CP titanium and Ti6Al4V alloy compositions provided by the manufacturer.

\begin{tabular}{ll}
\hline Material & Composition (wt.\%) \\
\hline Opaque bonding porcelain & $5.6 \mathrm{Al}_{2} \mathrm{O}_{3}, 25.5 \mathrm{SnO}_{2}, 50 \mathrm{SiO}_{2}, 5.3 \mathrm{~K}_{2} \mathrm{O}, 6.9 \mathrm{Na}_{2} \mathrm{O}, 2.1 \mathrm{BaO}_{2} .9 \mathrm{ZrO}_{2}, 0.6 \mathrm{ZnO}$ \\
CP titanium grade II & $99.6 \mathrm{Ti}, 0.041 \mathrm{Fe}, 0.108 \mathrm{O}, 0.014 \mathrm{C}, 0.009 \mathrm{~N}, 0.0014 \mathrm{H}$ \\
Ti6Al4V & $89 \mathrm{Ti}, 0.02 \mathrm{Fe}, 0.1 \mathrm{O}, 0.01 \mathrm{C}, 0.008 \mathrm{~N}, 6 \mathrm{Al}, 4.05 \mathrm{~V}, 0.003 \mathrm{H}$ \\
\hline
\end{tabular}


CP Titanium

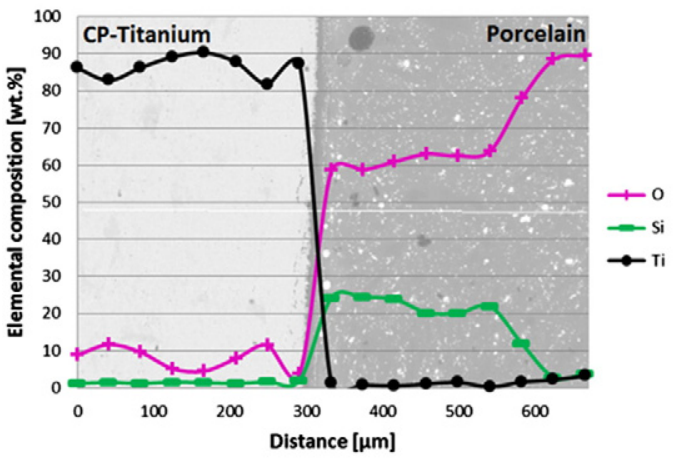

CP Titanium

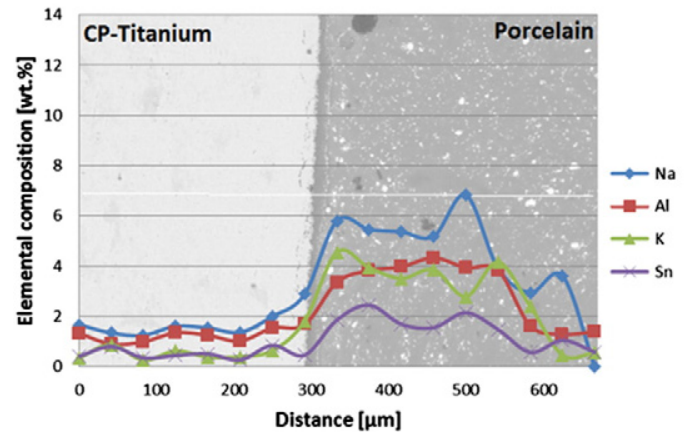

Ti6Al4V

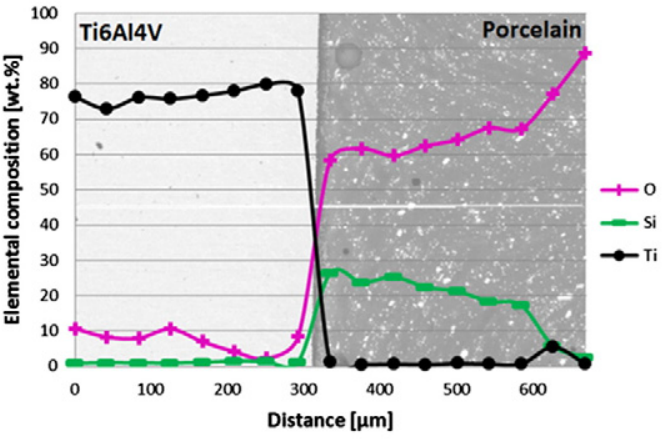

Ti6Al4V

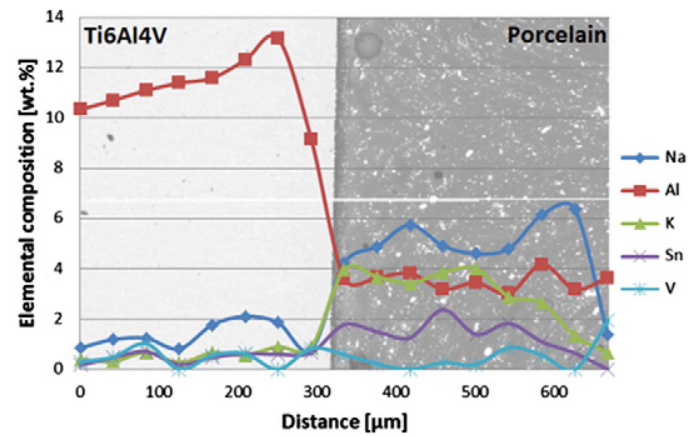

Fig. 3. Elemental diffusion profiles at the interface region of the porcelain-to-CP titanium and porcelain-to-Ti6Al4V specimens.

veneering porcelain, which increased from $81 \mathrm{GPa}$ (away from interface) to $90 \mathrm{GPa}$ (near the interface). The hardness at $90^{\circ}$ increased in titanium side from $176 \mathrm{HV}$ (away from the interface) to $330 \mathrm{HV}$ near the interface. At the veneering porcelain, hardness decreased from $805 \mathrm{HV}$ (away from interface) to $670 \mathrm{HV}$ (near the interface). Measurements at $10^{\circ}$ revealed differences mainly at the porcelain side as the porcelain thickness changed with the lateral distance to interface. The elastic modulus decreased from $81 \mathrm{GPa}$, at a distance from interface (x) of $400 \mu \mathrm{m}$ and porcelain thickness (t) of $250 \mu \mathrm{m}$, to $68 \mathrm{GPa}(\mathrm{x}=30 \mu \mathrm{m} ; \mathrm{t}=15 \mu \mathrm{m})$. Hardness also decreased from $776 \mathrm{HV} \quad(\mathrm{x}=400 \mu \mathrm{m} ; \mathrm{t}=250 \mu \mathrm{m})$ to $670 \mathrm{HV} \quad(\mathrm{x}=30 \mu \mathrm{m}$; $\mathrm{t}=15 \mu \mathrm{m})$.

The variation in elastic modulus and hardness measured across the porcelain-to-Ti6Al4V interface at 10 and $90^{\circ}$ is shown in Fig. 7. The elastic modulus of Ti6Al4V measured at $90^{\circ}$ remained constant at $150 \mathrm{GPa}$ from the bulk until the region near the interface. Also in porcelain, no significant change was detected in elastic modulus, from regions away from interface ( $83 \mathrm{GPa}$ ) until the interfacial region $(88 \mathrm{GPa})$. The hardness measurements at $90^{\circ}$ for Ti6Al4V showed a variation ranging from $370 \mathrm{HV}$, measured away from the interface, up to $465 \mathrm{HV}$ at the interfacial region. On the other side, porcelain hardness decreased from $810 \mathrm{HV}$ to $767 \mathrm{HV}$, measured from the bulk until the interfacial region. Measurements of elastic modulus and hardness at $10^{\circ}$ on Ti6Al4V did not significantly differ from those obtained at $90^{\circ}$. On the porcelain side, the elastic modulus showed a small decrease relative to that one obtained at $90^{\circ}$, being $81 \mathrm{GPa}$ near the interface. In this case, no significant variation of the elastic modulus could be observed with the porcelain thickness variation. However, hardness showed to be dependent on the porcelain thickness, as it was early demonstrated in Fig. 6. The hardness decreased from
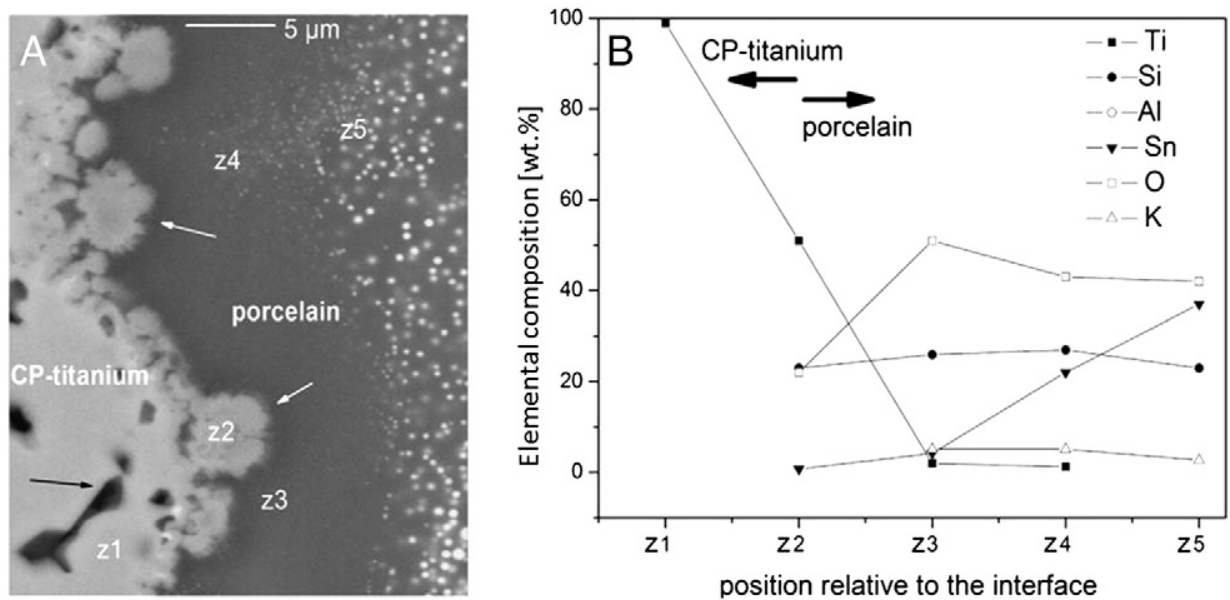

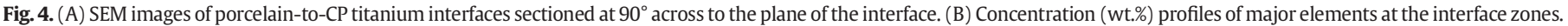



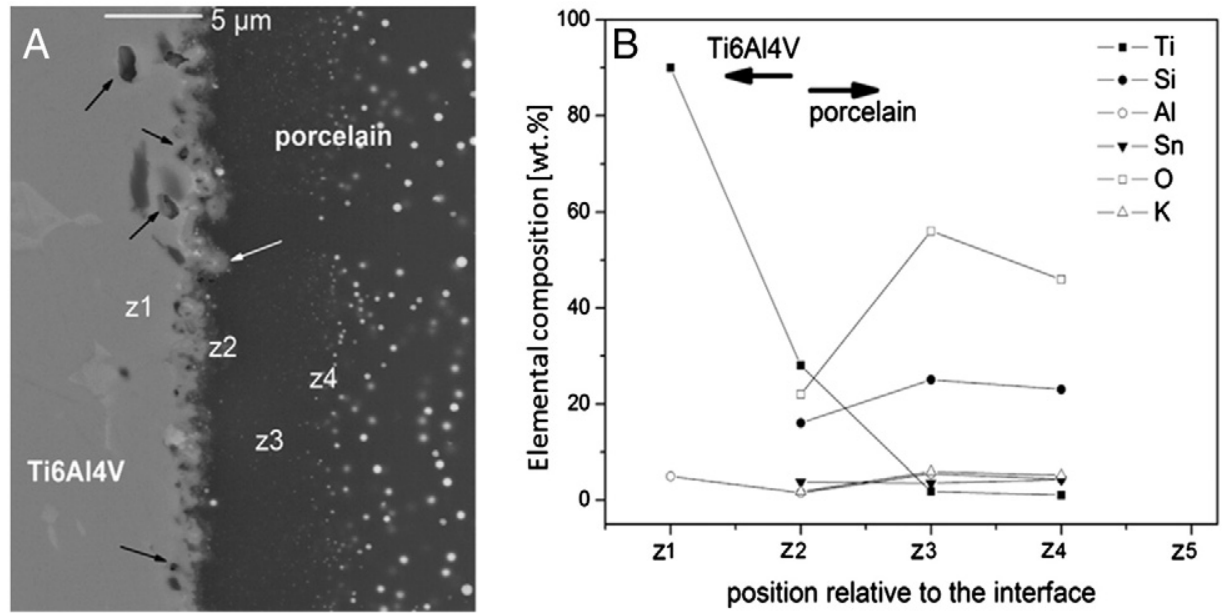

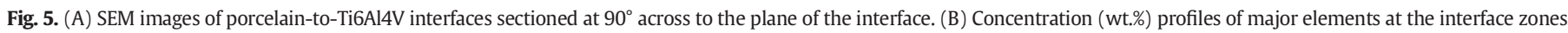

$800 \mathrm{HV}$ at a region away from the interface $(\mathrm{x}=400 \mu \mathrm{m} ; \mathrm{t}=250 \mu \mathrm{m})$ to $550 \mathrm{HV}$ at the interfacial region $(\mathrm{x}=30 \mu \mathrm{m} ; \mathrm{t}=15 \mu \mathrm{m})$.

SEM images of the indents revealed plastic flow on the CP titanium surface (Fig. 8A). Radial cracks were detected (see white arrows) after indentation on dental porcelain at 10-190 $\mu \mathrm{m}$ away from the porcelain-to-titanium interface on a $10^{\circ}$ angle cross-section (Fig. $8 \mathrm{~B}$ and $\mathrm{C}$ ). Cracks are more widespread close to the $10^{\circ}$ angle crosssection interface since the porcelain thickness decreases (Fig. 8B). Radial cracks were not detected after indentation on the dental porcelain at $450 \mu \mathrm{m}$ away from the interface cross-sectioned at a $10^{\circ}$ angle (Fig. 8D). Also, cracks were not detected across $90^{\circ}$ angle cross-section interfaces.

\section{Discussion}

\subsection{Chemical analysis of metal-ceramic interfaces}

Crystalline phases such as $\mathrm{ZrO}_{2}$ (Fig. 2) and mainly $\mathrm{SnO}_{2}$ act as an opaque layer covering the dark color of the metallic substrate $[1,5,29]$. The vitreous phase composed of feldspar provides the appearance that mimics natural tooth structures. During firing cycle of the opaque porcelain layer, a chemical reaction between the titanium-based substrate and porcelain took place. Such reactivity promotes the diffusion of Ti into porcelain during the firing process (identified by black arrows) as detected by SEM/EDS (Figs. 4A and 5A). The high reactivity of the metallic substrate may have promoted a higher diffusion of Ti into the veneering porcelain, forming a reaction zone. Also, previous findings revealed the inter-diffusion of $\mathrm{Ti}$, Si an $\mathrm{O}$ along veneering porcelain-to-titanium [30,31].

Könönen and Kivilahti [30] reported on the chemical reaction between titanium and silica from porcelain forming a $\mathrm{Ti}_{5} \mathrm{Si}_{3} \mathrm{O}$ phase which can cause the fracturing of the veneering porcelain fused to metal. Intermediate coatings like $\mathrm{SiO}_{2}, \mathrm{SiO}_{2}-\mathrm{TiO}_{2}, \mathrm{ZrSiN}$ or TiN could act as oxygen diffusion barriers on the metal substrate during the heat treatment of porcelain bonders and dental porcelains, enhancing the metal-porcelain bond strength, as reported by previous studies [23-25,32]. Suansuwan \& Swain [21] reported on a diffusion of Al and O elements from dental porcelain (Titankeramik) into CP titanium during bonding. That last study did not report significant inter-diffusion of Ti and Si elements from the substrate and porcelain, respectively, at the interface. Previous studies also reported on the mutual inter-diffusion between different metallic substrates ( $\mathrm{NiCr}$, AuPdPt) and dental porcelain [26,33]. However, the chemical reactivity of titanium mainly above $800{ }^{\circ} \mathrm{C}$ was higher than that reported on veneering porcelain-to- $\mathrm{NiCr}$ [2,33]. Mutual inter-diffusion and simultaneous solid-state reactions are responsible for the ceramic-to-metal bonding [33]. The diffusion of
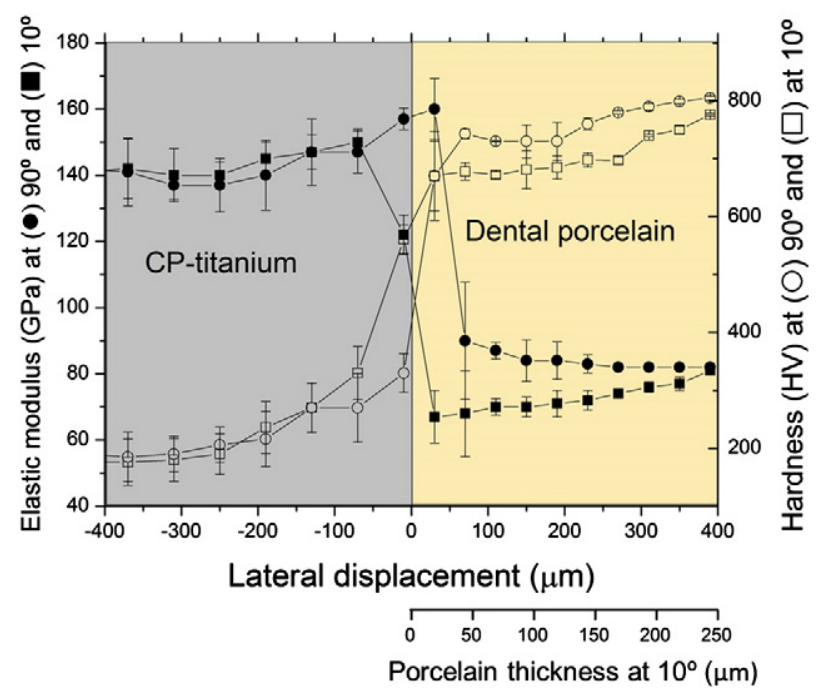

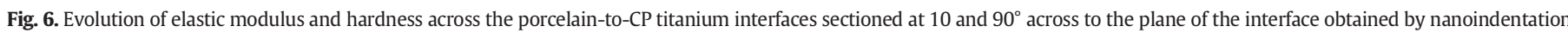
tests. 

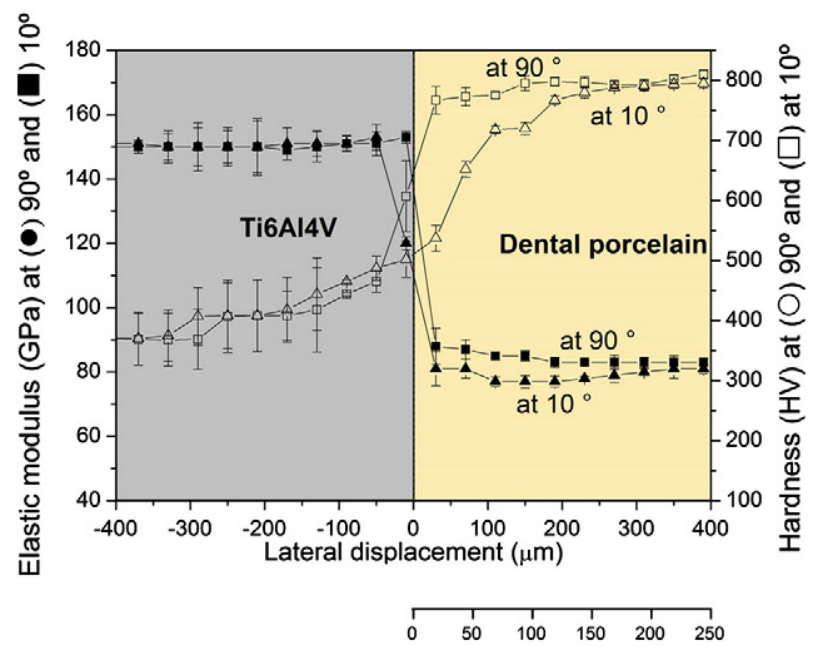

Porcelain thickness at $10^{\circ}(\mu \mathrm{m})$

Fig. 7. Evolution of elastic modulus and hardness across the porcelain-to-Ti6Al4V interfaces sectioned at 10 and $90^{\circ}$ across to the plane of the interface obtained by nanoindentation tests.

porcelain elements into titanium has been explained in terms of the titanium reducing most oxides in the porcelain during porcelain firing, forming reaction products [21]. Elemental analysis by SEM/EDS has shown to be very useful for better understanding the chemical component of adhesion in metal-ceramic bonding systems, although advanced techniques (e.g. transmission electron microscopy) are required to validate such findings $[2,21,33]$.

\subsection{Mechanical analysis of metal-ceramic interfaces}

A match of physical-mechanical properties between metallic substrates and porcelain is crucial to achieve good performance of porcelain-to-metal assembly in the oral cavity $[1,2,34]$. For instance, an excessive thermal mismatch can result in the formation of critical thermal residual stresses at metal-ceramic interface that can account for a premature failure of the bond. The metal-ceramic bond strength may also be affected by the ability of the materials to behave similarly when superimposed external loads are applied. Hence, compatible elastic properties of materials to bond are always preferred in order to avoid interfacial stresses due to elastic property mismatches [35]. The elastic modulus mismatch recorded for porcelain-to-CP titanium was higher than that recorded for porcelain-to-Ti6Al4V, $70 \mathrm{GPa}$ and $65 \mathrm{GPa}$, respectively. This means that Ti6Al4V may perform better under clinical conditions from the point of view of mechanical fatigue behavior, as stresses of lower magnitude are expected to develop at the metalceramic interface $[2,6,26,27,36]$. Previous findings revealed better mechanical behavior of veneering porcelain-to-titanium alloy interfaces in bending tests compared to that of veneering porcelain-to-CP titanium ones [21,24].

Titanium alloys are very attractive in biomedical engineering for the production of healthcare goods due to their appropriate mechanical properties and corrosion resistance $[1,14,38,39]$. Fortunately nowadays, the application of titanium alloys is dictated by requirements related to corrosion and biocompatibility $[1,14,39]$. Possible cytotoxic effects associated to the presence of $\mathrm{Al}$ and $\mathrm{V}$ ions released from Ti6Al4V alloys have been reported in the literature [38]. Pan et al. [38] studied the growth of endothelial cells in vitro on Ti6Al4V alloy and they verified a permanent oxidative stress of cells followed by a decrease of the metabolic activity, radical formation and antioxidant defense molecules production. Furthermore, several tests have been performed to classify new alloys and their elements considering cellular toxicity, corrosion, biocompatibility $[14,38,39]$. However, novel titanium alloys such as Ti13Nb13Zr, Ti15Mo2.8Nb or Ti-15Zr-4Nb-4Ta-0.2Pd have shown higher biocompatibility than that for Ti6Al4V. Additionally, those novel alloys have high mechanical strength and corrosion resistance [14,38].

The hardness evaluation across the interface revealed a tendency of both CP titanium and Ti6Al4V to increase their hardness when approaching veneering porcelain interface (Figs. 6 and 7). This fact may be explained by the diffusion of porcelain elements in a significant extent (Fig. 3 ) to the metal side, resulting in a graded-like transition of hardness from that of metal to that of porcelain. On the other hand, no metallic elements were found in the porcelain side, and consequently, no major variations were found in porcelain hardness.

Nanoindentation tests performed at different angles $\left(90^{\circ}\right.$ and $\left.10^{\circ}\right)$ relative to the interfaces allow comparing mechanical properties of different types of layered ceramics fused to metal. That analysis allowed us to investigate stress/strain fields induced during indentation test across interfaces oriented differently with respect to the displacement axis of the indenter. With respect to the nanoindentation tests performed to metal-ceramic interfaces sectioned at $10^{\circ}$ (Figs. 6-8), they allowed to assess variation of the mechanical properties relative to the porcelain thickness. Such veneering porcelain thickness varies considering the geometry of prosthetic crowns. For instance, the thickness of the veneering porcelain can be lower at gingival zones than those at occlusal (masticatory) zones. The elastic modulus and hardness of porcelain measured in the porcelain-to-CP titanium sample showed to decrease for lower porcelain thicknesses. Regarding veneering porcelain-toTi6Al4V, no significant variation in elastic modulus was detected with porcelain thickness variation, as observed for CP titanium. However, the variation of hardness could be observed. The higher reactivity of $\mathrm{CP}$ titanium, which is a known feature of this material, also demonstrated by the formation of a broad metal-ceramic reaction zone (Fig. 3), can explain its different behavior relative to Ti6Al4V.

It was noticed that the reactivity of titanium during the veneering porcelain firing promoted an asymmetric profile of the mechanical behavior across the interfaces. That is an important issue considering that there is a variation of layer thickness of porcelain and metallic substrates in the margin of metal-ceramic dental restorations [1,37]. Also, cracks can frequently occur at thin porcelain layers such as at margin of prosthetic crowns taking into account a variation of porcelain thickness caused by the technique sensitivity. The thickness of veneering ceramic was reported to affect the mechanical strength of metal-ceramic interfaces $[1,37]$. A uniform thickness is recommended to minimize the formation of microcracks, which may occur during the firing of the ceramic $[1,37]$. However, the processing of veneering porcelains onto titanium-based substrates is still a meticulous work in ceramic buildup that needs to follow all the requirements of technical skill.

\section{Conclusions}

The chemical and mechanical behavior of veneering dental porcelain fused to titanium-based substrates were accessed by nanoindentation in

Table 2

Bulk properties of CP titanium, Ti6Al4V and dental porcelain.

\begin{tabular}{llc}
\hline Material & Hardness (HV) & Elastic modulus (GPa) \\
\hline Opaque bonding porcelain & $780 \pm 21$ & $81 \pm 4$ \\
CP titanium grade II & $180 \pm 4$ & $136 \pm 6$ \\
Ti6Al4V & $351 \pm 12$ & $148 \pm 7$ \\
\hline
\end{tabular}



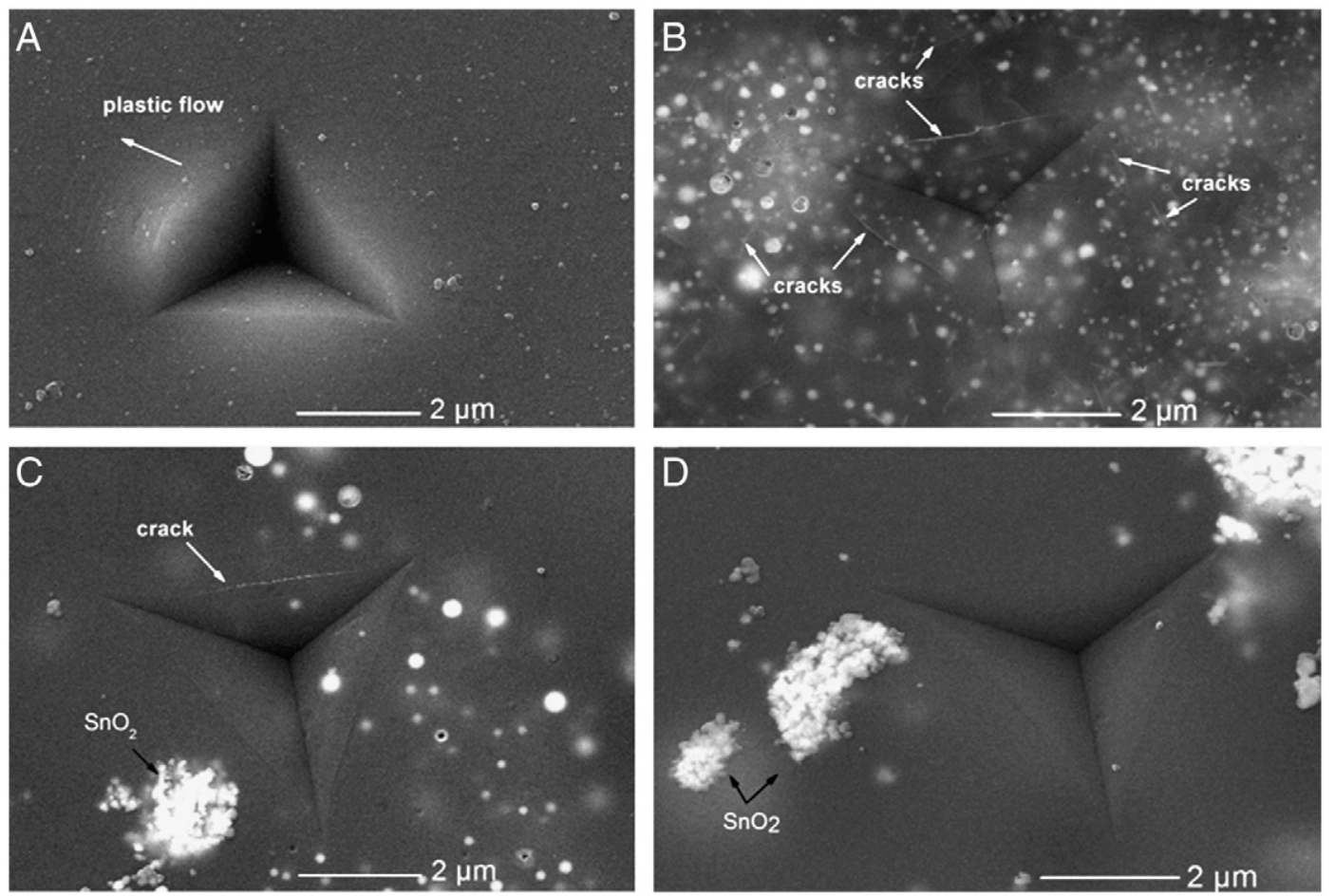

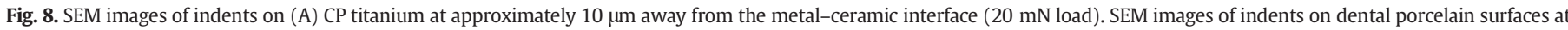

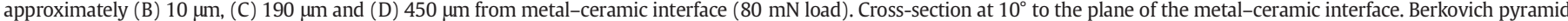
tip (apex angle of $143^{\circ}$, shape function determined by Oliver and Phar method).

this work. Within the limitation of the present study, the following conclusions can be drawn:

- A wider reaction zone was noticed at the veneering porcelain fused to commercially pure $(\mathrm{CP})$ titanium relative to veneering porcelain fused to Ti6Al4V. Also, a higher incidence of defects was found at the veneering porcelain fused to $\mathrm{CP}$ titanium than that on Ti6Al4V substrates;

- The reactivity between $\mathrm{CP}$ titanium and veneering porcelain during thermal treatment induced a high diffusion of Ti ions into porcelain followed by the formation of defects;

- The elastic modulus mismatch recorded for porcelain-to-CP titanium was higher than that recorded for porcelain-to-Ti6Al4V interfaces;

- The hardness evaluation across the interface revealed a tendency of both CP titanium and Ti6Al4V to increase their hardness when approaching veneering porcelain interface. The diffusion of elements between the materials during thermal treatment can affect the hardness across the interface;

- Cracks were noticed on thin porcelain layers after nanoindentation tests indicating an influence of the porcelain thickness on the mechanical behavior of the porcelain-to-titanium interfaces;

- Nanoindentation tests can be a useful technique to evaluate the mechanical behavior across multilayered veneering porcelain fused to different substrates. Also, the influence of veneering porcelain thickness can be studied by cross-sectioning the porcelainsubstrate assemblies at different angles relative to the direction of the interfaces.

\section{Acknowledgments}

The authors acknowledge the financial support provided by AlBan Programme (cod. E06D103407BR), the Erasmus student exchange program of the CEC and FCT (PTDC/CTM/67500/2006, SFRH/BPD/87435/ 2012), the Scientific Research Community on Surface Modification of
Materials funded by the Flemish Science Foundation (WOG-FWOVlaanderen) and CAPES (Brazil) Foundation.

\section{References}

[1] K.J. Anusavice, Phillip's Science of Dental Materials, 11th ed. WB Saunders, St Louis, 2003

[2] J.C.M. Souza, R.M. Nascimento, A.E. Martinelli, Surf. Coat. Technol. 205 (2010) 787-792.

[3] H.W. Roberts, D.W. Berzins, K. Moore, D.G. Charlton, J. Prosthodont. 18 (2009) 188-194.

[4] K. Könönen, J. Kivilahti, J. Dent. Res. 80 (2001) 848-854.

[5] J.C.M. Souza, R.M. Nascimento, A.E. Martinelli, Cerâmica 53 (2007) 288-294.

[6] B. Henriques, D. Soares, F.S. Silva, Mater. Sci. Eng. C 32 (2012) 2374-2380.

[7] W.M. Palin, G.J.P. Fleming, P.M. Marquis, J. Dent. 29 (2001) 443-449.

[8] A. Sadeq, Z. Cai, R.D. Woody, A.W. Miller, J. Prosthet. Dent. 90 (2003) 10-17.

[9] M.E. Kreissl, T. Gerds, R. Muche, G. Heydecke, J.R. Struby, Clin. Oral Implants. Res. (2007) $720-726$

[10] B.E. Pjetursson, K. Tan, N.P. Lang, U. Brägger, M. Egger, M. Zwahlen, Clin. Oral Implants. Res. 15 (2004) 625-642.

[11] B.E. Pjetursson, U. Brägger, N.P. Lang, M. Zwahlen, Clin. Oral Implants. Res. 18 (2007) 97-113.

[12] L. Guo, X. Liu, Z. He, J. Gao, J. Yang, T. Guo, Mater. Lett. 14 (2007) 2204-2206.

[13] G. Isgró, C.J. Kleverlaan, H. Wang, A.J. Feilzer, Thermal dimensional behavior of dental ceramics, Biomater 25 (2004) 2447-2453.

[14] M. Niinomi, Sci. Technol. Adv. Mater. 4 (2003) 445-454

[15] N. Schiff, B. Grosgpgeat, M. Lissac, F. Dalard, Biomater 23 (2002) 1995-2002.

[16] M. Adachi, J.R. Mackert Jr., E.E. Parry, C.W. Fairhurst, J. Dent. Res. 69 (1990) 1230-1235.

[17] H. Kimura, C.J. Horng, M. Okazaki, J. Takahashi, Dent. Mater. 9 (1990) 91-99.

[18] R.R. Wang, K.K. Fung, J. Prosthet. Dent. 77 (1997) 423-434.

[19] S. Atsü, S. Berksun, J. Prosthet. Dent. 84 (2000) 567-574.

[20] I.R. Bondiolli, M.A. Bottino, J. Prosthet. Dent. 91 (2004) 541-547.

[21] V. Suansuwan, M.V. Swain, J. Dent. 31 (2003) 509-518.

[22] M.J. Tholey, J.N. Waddell, M.V. Swain, Dent. Mater. 23 (2007) 822-828.

[23] S. Park, Y. Kim, H. Lim, G. Oh, H. Kim, J.L. Ong, K. Lee, Surf. Coat. Technol. 203 (2009) 3243-3249.

[24] J. Bieniás, B. Surowska, A. Stoch, H. Matraszek, M. Walczak, Dent. Mater. 25 (2009) $1128-1135$.

[25] H. Zhang, T.W. Guo, Z.X. Song, X.J. Wang, K.W. Xu, Surf. Coat. Technol. 201 (2007) 5637-5640.

[26] B. Henriques, D. Soares, F.S. Silva, Mater. Sci. Eng. A 528 (2011) 1415-1420

[27] B. Henriques, M. Gasik, D. Soares, F.S. Silva, J. Mech. Behav. Biomed. Mater. 13 (2012) 206-214.

[28] S. Milis, J.-P. Celis, Thin Solid Films 288 (1996) 202-211. 
[29] J.L. Ong, D.W. Farley, Dent. Mater. 16 (2000) 20-25.

[30] M. Könönen, J. Kivilahti, J. Biomed. Mater. Res. 28 (1994) 1027.

[31] S. Zinelis, X. Barmpagadaki, C. Vergosc, M. Chakmakchia, G. Eliades, Dent. Mater. 26 (2010) 264-273.

[32] C. Paluszkiewicz, A. Stoch, Vib. Spectrosc. 35 (2004) 183-187.

[33] C. Hegedüs, L. Daróczi, V. Kökényesi, D.L. Beke, J. Dent. Res. 81 (2002) 334-337.

[34] M. Chakmakchi, G. Eliades, S. Zinelis, J. Prosthodont. Res. 53 (2009) 166-171.
[35] M. Gasik, M.A. Kawasaki, Y. Kang, Mater. Sci. Forum 492 (2005) 9-14.

[36] F. Toptan, A.C. Alves, B. Henriques, J.C.M. Souza, F.S. Silva, L.A. Rocha, E. Ariza, J. Mech. Behav. Biomed. Mater. 20 (2013) 327-337.

[37] M. Özcan, J. Oral Rehabil. 30 (2003) 265-269.

[38] Y. Ozakaki, Curr. Opin. Solid State Mater. Sci. 5 (2001) (2001) 45-53.

[39] J. Pan, H. Liao, C. Leygraf, D. Thierry, J. Li, J. Biomed. Mater. Res. 40 (1998) 244-256 